Objectives To detect different types to generate a shortterm politic of prevention in pedestrians' lesions, cyclists and motorcyclists.

Method A multidimensional descriptive study, of transverse cut of the lesions by transport of vulnerable happened in 2007 at 2009 in El Carmen about registrations of the Unit Sentry of lesions, by means of SPAD 4.01 classifying according to vehicle, age group, sex, events and others.

Results Above 6950 registrations 530 events were studied; The factorial analysis of multiple correspondences with partition in classes using as active variables to vehicle type, sex, age and activity gave five different classes as a result: bicycles, of 0 to 9 years, passenger, without tally, ambulatory treatment, without elements of security in $24.15 \%$; pedestrians, males, 50 to more years, collision with vehicle, hospitalised $15.09 \%$; motorcyclists, of 10 to 19 years, driver, fall of the vehicle, activity recreation $24.34 \%$; motorcyclists, of 20-39 years, driver, fall, carrying out activities of the daily life $27.92 \%$ and $8.49 \%$ from 40 to 49 years, males, day and evening schedule, in bicycle or motorcycle, without tally, derived, without security.

Conclusions The multivaried analysis classifies a complex reality and it puts inadverted regularities and differencies allowing to suggest specific actions in prevention.

\title{
0805 MULTIFACTORIAL STUDY OF LESIONS FOR TRANSPORT IN VULNERABLE GROUPS-JUJUY-ARGENTINA-YEARS 2007-2009
}

LE Leinecker*, A Chalabe, B Zumbay, Ovega Correspondence: Hospital NTRA, SRA. DEL CARMEN, Area v, Jujuy, Argentina 